\title{
CORRESPONDENCE
}

\section{Rapid sequence induction with fibrescope: An uncommon practice!}

\section{Gaurav S. Tomar, Indu Kapoor, Ashish Bindra, Charu Mahajan}

We report a case of a 32-year-old male patient with high cervical vertebra (C1, C2) body fracture with canal compromise following road traffic accident. He presented to emergency department (ED) with the loss of power in all four limbs, poor cough and gag reflex with Glasgow Coma Scale of 15. He was shifted to Neurosurgical Intensive Care Unit (NICU) for further evaluation and management. He was apparently well in NICU for a day when he gradually developed difficulty in breathing. On clinical examination, his respiration was predominantly abdomino-thoracic. On auscultation, the chest was silent on the left side. Chest X-ray on day 2 showed a completely collapsed lung on the left side [Figure 1]. Although he was maintaining the oxygen saturation of $>92 \%$ with oxygen via face mask $(5 \mathrm{~L} / \mathrm{min})$ with borderline arterial blood gas (ABG) analysis showing $\mathrm{pH} 7.49, \mathrm{PaO}_{2} 60 \mathrm{mmHg}$, $\mathrm{PaCO}_{2} 45 \mathrm{mmHg}$ and $\mathrm{HCO}_{3} 29.1 \mathrm{mM} / \mathrm{L}$. In view of the chest $\mathrm{X}$-ray and to avoid the clinical deterioration, tracheal intubation was planned with awake fibreoptic technique under tracheal blocks. However, the nursing staff informed about the non-fasting status of the patient. As it was a case of cervical injury, a fibreoptic intubation with rapid sequence induction (RSI) was planned for securing the airway. He was premedicated with ranitidine $50 \mathrm{mg}$, metoclopromide $10 \mathrm{mg}$ and glycopyrrolate $0.2 \mathrm{mg}$ via intravenous (IV) route. Simultaneously, the technician was asked to keep the

Department of Neuroanaesthesiology and Critical Care, Neuroscience Centre, All India Institute of Medical Sciences, New Delhi, India

Address for correspondence:

Dr. Indu Kapoor, Department of Neuroanaesthesiology and Critical Care, Neurosciences Centre, All India Institute of Medical Sciences, New Delhi - 110 029, India. E-mail: dr.indu.me@gmail.com fibrescope ready with endotracheal tube railroaded over. Preoxygenation for $5 \mathrm{~min}$ was followed by induction with fentanyl $150 \mathrm{mcg}$ and propofol $100 \mathrm{mg}$ via IV route. Following the loss of verbal response, Sellicks manoeuvre was performed by a fellow anaesthesiologist. Succinylcholine $100 \mathrm{mg}$ IV bolus dose was given to facilitate the endotracheal intubation. His trachea was intubated with ease in the first attempt by the aid of fibreoptic bronchoscope (FOB) and tube position was confirmed while removing FOB from the trachea. Once stabilised, his tracheobronchial tree was examined with FOB. A thick mucus plug was noticed over left main bronchus later cleared with suctioning and irrigation with $0.9 \%$ normal saline. Subsequent chest X-ray [Figure 2] and ABG after $2 \mathrm{~h}$ of elective

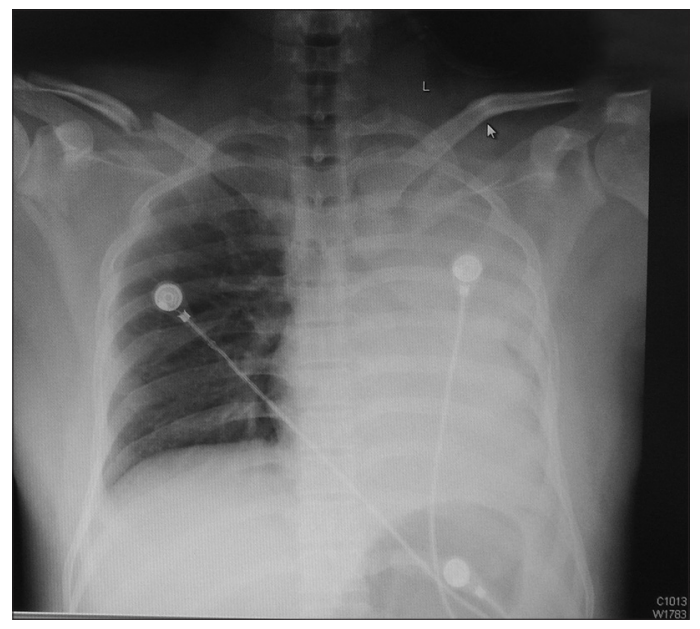

Figure 1: Chest X-ray showing collapsed lung on left side

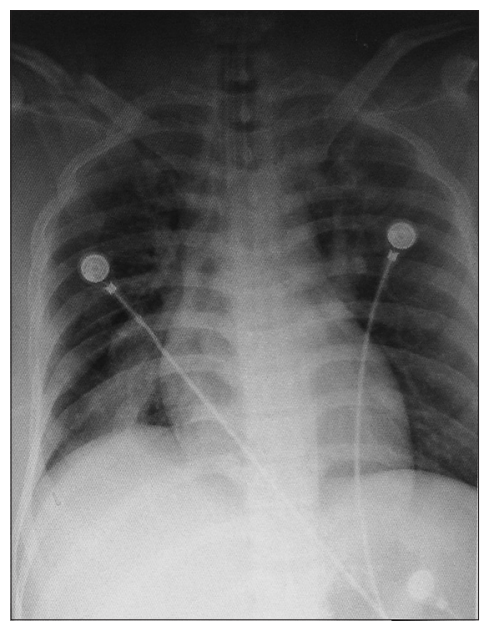

Figure 2: Completely expanded left sided lung field after mucus plug removal 
ventilation showed significant improvement. Next day, the patient was operated for cervical spine fracture with the uneventful intraoperative course.

RSI is the preferred method of endotracheal intubation in the ED as it results in the rapid induction and neuromuscular blockade. ${ }^{[1]}$ This is important in patients in particular with road traffic accident who are considered full stomach and at much greater risk for vomiting and aspiration. RSI has been cited as the most common method used to secure the airway in Intensive Care Unit patients also. ${ }^{[2]}$ Over the past 10 years, the method of RSI has emerged with the introduction of new drugs, knowledge and equipment. According to a recent survey of both consultant and trainee, anaesthetists showed that practice is varied. Several alternatives to succinylcholine and inducing agents are used by many anaesthetists. ${ }^{[3]}$ Since the early 1970s, there have been reports of hyperkalaemia and life-threatening arrhythmias in spinal cord injury after succinylcholine administration. According to Martyn and Richtsfeld, 'quadriplegics and paraplegics with persistent paralysis could have the potential for succinylcholine hyperkalaemia throughout life' ${ }^{[4]}$ While succinylcholine may be safely used within $24 \mathrm{~h}$ of injury, ${ }^{[5]}$ it should be avoided afterwards. Many others would view $<48 \mathrm{~h}$ after spinal cord trauma, a safe period to use succinylcholine. In our case, we introduced succinylcholine after confirming the normal serum potassium level $\left(\mathrm{S} . \mathrm{K}^{+}: 4.2 \mathrm{mEq} / \mathrm{L}\right)$. The intubating fibrescope has been used to facilitate intubation in difficult laryngoscopy or failed intubation. RSI is generally performed with a conventional laryngoscope. Fibreoptic intubation is usually not recommended as a first line management while performing RSI. However, it may be used as an alternative to different blades of a laryngoscope or gum elastic bougies when intubation fails during RSI. ${ }^{[6]}$ In skilled hands, fibreoptic intubation can be rapidly achieved with few complications and allows immediate diagnostic bronchoscopy and therapeutic intervention if required. ${ }^{[7]}$ Although, in a simulated RSI scenario, fibreoptic intubation has been found to be feasible, ${ }^{[6]}$ there is no such reported incident in literature. While some might consider tracheal blocks to be possibly contraindicated in patients with high risk of gastric aspiration, it is believed by the most authorities actually to decrease the risk, by decreasing the risk of coughing and gag reflex during intubation. However, these blocks do not provide definitive protection against aspiration. In our case, we performed RSI and tracheal intubation with FOB in a patient with full stomach suffering from a cervical spine injury. Through our case report, we wish to highlight and emphasise the safety, validity and feasibility of FOB for RSI under emergent conditions in experienced hands.

\section{Financial support and sponsorship} Nil.

\section{Conflicts of interest}

There are no conflicts of interest.

\section{REFERENCES}

1. Walls RM, Brown CA $3^{\text {rd }}$, Bair AE, Pallin DJ; NEAR II Investigators. Emergency airway management: A multi-center report of 8937 emergency department intubations. J Emerg Med 2011;41:347-54.

2. Schwartz DE, Matthay MA, Cohen NH. Death and other complications of emergency airway management in critically ill adults. A prospective investigation of 297 tracheal intubations. Anesthesiology 1995;82:367-76.

3. Morris J, Cook TM. Rapid sequence induction: A national survey of practice. Anaesthesia 2001;56:1090-7.

4. Martyn JA, Richtsfeld M. Succinylcholine-induced hyperkalemia in acquired pathologic states: Etiologic factors and molecular mechanisms. Anesthesiology 2006;104:158-69.

5. Cooperman LH. Succinylcholine-induced hyperkalemia in neuromuscular disease. JAMA 1970;213:1867-71.

6. Dravid RM, Pandit JJ, lyer R, Popat M. Fibreoptic intubation for rapid sequence induction. Eur $\mathrm{J}$ Anaesthesiol 2000; $17: 65$.

7. Tofts RP, Alvarez M, Oliveira E. Fiber-optic bronchoscopy for routine intubation in the ICU: Review of safety, complications and usefulness as a diagnostic adjunct. Chest 2010;138:218.

This is an open access article distributed under the terms of the Creative Commons Attribution-NonCommercial-ShareAlike 3.0 License, which allows others to remix, tweak, and build upon the work non-commercially, as long as the author is credited and the new creations are licensed under the identical terms.

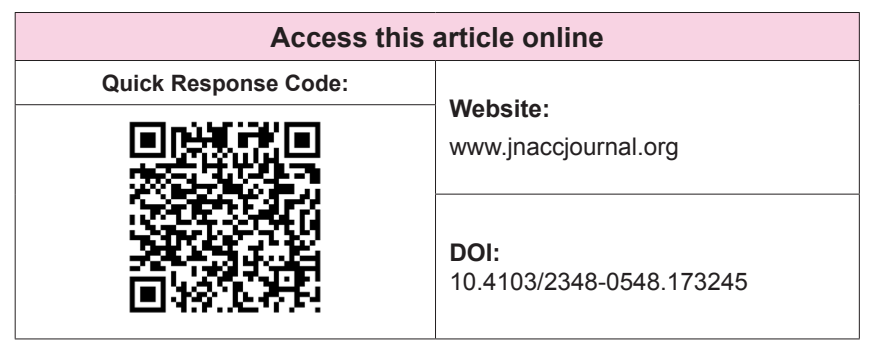

